\title{
The limits of laparoscopic treatment in severe acute pancreatitis
}

\author{
Limitele laparoscopiei în drenajul pancreatitei acute severe
}

Ramona ILIESCU ${ }^{1}$, Ştefania MANOLESCU ${ }^{1}$, Mihnea AVRAM ${ }^{1}$, Bogdan GASPAR ${ }^{1,2}$, Sorin PĂUN ${ }^{1,2}$, Mircea BEURAN ${ }^{1,2}$, Alexandru Laurenţiu CHIOTOROIU ${ }^{1}$

${ }^{1}$ Spitalul Clinic de Urgenţă, Bucureşti, România

2Universitatea de Medicină şi Farmacie „Carol Davila“, Bucureşti, România

\section{REZUMAT}

Pancreatita acută severă reprezintă o patologie dificil de tratat, cu o rată a mortalității ridicată. Fezabilitatea abordului laparoscopic în tratamentul pancreatitei severe este încă în dezbatere. Acesta este un studiu retrospectiv incluzând 132 de pacienți cu pancreatită acută severă internați în clinica de Chirurgie Generală a Spitalului Clinic de Urgență București în perioada ianuarie 2016-decembrie 2018, dintre care 11 pacienți (8,3\%) au beneficiat de tratament chirurgical laparoscopic al patologiei enunțate. Dintre cei 132 de pacienți, 107 pacienți $(81 \%)$ au beneficiat de tratament conservator al pancreatitei acute severe. La 14 pacienți $(10,6 \%)$, s-a efectuat necrectomie pe cale deschisă, 11 pacienți $(8,3 \%)$ au beneficiat de necrectomie laparoscopică urmată de drenaj extern pentru colecții lichidiene masive și/sau necroză infectată în faza acută a episodului de pancreatită acută severă, iar conversia la operația deschisă s-a realizat în 4 cazuri (4/11). La 8 pacienți $(6,1 \%)$ cu pseudochist pancreatic sau abces s-au realizat debridare laparoscopică intracavitară și drenajul extern fără complicații postoperatorii ale acesteia. Cea mai frecventă cauză a pancreatitei acute severe a fost consumul de etanol. Dintre cei $11 \mathrm{cu}$ necrectomie laparoscopică, 5 pacienți au prezentat complicații postoperatorii: colită cu Clostridium difficile, hemoragie pe tubul de dren, pleurezie bazală stângă, disfuncție multiplă de organ. În concluzie, abordul laparoscopic poate fi o alternativă terapeutică în tratamentul pancreatitei acute severe în cazuri selecționate.
\end{abstract}

Cuvinte cheie: pancreatită acută severă, laparoscopie, tratament chirurgical, drenaj

\begin{abstract}
Severe acute pancreatitis is a pathology difficult to treat with a high mortality rate. The feasibility of laparoscopic approach in the treatment of severe pancreatitis is still under discussion. Retrospective study that included a total of 132 patients diagnosed with severe acute pancreatitis admitted in General Surgery Clinic of the Bucharest Emergency Clinical Hospital between January 2016 and December 2018, of which 11 patients $(8.3 \%)$ received laparoscopic surgical treatment for the reported pathology. From a total of $132 \mathrm{pa}-$ cients, 107 patients (81\%) received conservative treatment for the severe pancreatitis, 14 patients $(10.6 \%)$ benefited of classical necrectomy, 11 patients $(8.3 \%)$ benefited of laparoscopic necrectomy followed by external drainage for massive liquid collections and / or infected necrosis in the acute phase of severe pancreatitis, and conversion to open surgery was performed in 4 cases (4/11). For 8 patients $(6.1 \%)$ who had pancreatic pseudocyst or abscess, intracavitary laparoscopic debridement and external drainage was performed without any complications. The most common cause of severe acute pancreatitis was ethanol consumption. Of the 11
\end{abstract}


patients with laparoscopic necrectomy, 5 patients experienced postoperative complications: Clostridium difficile colitis, drainage tube haemorrhage, left basal pleural effusion, multiple organ dysfunction. As a conclusion, laparoscopic approach offers an alternative in the treatment of severe acute pancreatitis in selected cases.

Keywords: severe acute pancreatitis, laparoscopy, surgical treatment, drainage

\section{INTRODUCERE}

În ultimii 20 ani, tratamentul pancreatitei acute (PA) a suferit modificări, chirurgia deschisă fiind recomandată în cazurile severe de boală şi în complicaţiile infecţioase ale acesteia. Astfel, managementul chirurgical se aplică în următoarele cazuri: pentru diagnosticul de certitudine (laparotomie exploratorie), sindromul de compartiment abdominal, infectarea necrozei, ischemia sau necroza intestinală neocluzivă, fistula enterocutanată, complicaţii vasculare, pseudochist pancreatic sau în cazul în care dorim să prevenim recurenţa pancreatitei acute severe (1).

Pancreatita acută este o afecţiune cu severitate variabilă, în 20-30\% dintre cazuri întâlnindu-se forma severă, iar mortalitatea generală la aceşti pacienţi poate ajunge până la $5-10 \%(2,10)$.

Tabloul clinic al pacientului cu PA descrie o durere abdominală continuă, cu sediul epigastric iniţial, de intensitate mare şi iradiere în bară, însoţită de creşterea valorilor lipazei de 3 ori faţă de normal. Pancreatita acuta severă (PAS) se caracterizează prin prezenţa unei manifestări descrise la PA, plus unul dintre următoarele criterii: zonă de necroză pancreatică, pseudochist sau ţesut pancreatic infectat, lezarea funcţională a altor organe. Printre complicaţiile PA, putem evidenţia: plastron peripancreatic, abces, peritonită, flegmon retroperitoneal, hemoragie, pseudochist pancreatic (care, în $50 \%$ dintre cazuri, poate regresa spontan), chisturi pancreatice (infectate / neinfectate) sau fistule ale tractului digestiv $(3,9)$.

În ceea ce priveşte diagnosticarea acestei afecţiuni, examenul CT abdomino-pelvin cu substanţă de contrast este considerat gold standard pentru stabilirea diagnosticului cert de necroză pancreatică sau a colecţiilor peripancreatice. Suprainfectarea colecţiilor peripancreatice se poate realiza cu următoarele microorganisme: E. coli (35\%), Klebsiella pneumoniae (24\%), Enteroccocus (24\%), Staphylococcus (14\%) sau Pseudomonas (11\%) (5).

PAS reprezintă o afecţiune greu de tratat, abordul chirurgical laparoscopic rămâne încă o soluţie de tratament relativ eficientă şi fezabilă în cazurile atent selecţionate, iar pentru a aplica acest tip de chirurgie minimum invazivă, trebuie avute în vedere intervalul de timp de la debutul afecţiunii, gradul de disfuncţie al organului şi localizarea tesutului necrotic în abdomen $(4,6)$.

Astfel, morbiditatea şi mortalitatea rămân crescute în cazul pancreatitei acute necrotice. Tratamentul chirurgical radical este de preferat a fi temporizat cât mai mult posibil, pentru a menţine un nivel scăzut al morbidităţii şi mortalităţii. Tehnicile minimum invazive, laparoscopice, au rolul de a evita consecinţele unei operaţii de mare amploare, invazivă, însă pot, în acelaşi timp, să subestimeze gravitatea leziunii şi chiar să piardă din vedere unele complicaţii apărute în evoluţia naturală a bolii (pseudochist pancreatic, abces, lichid la nivelul cavităţii peritoneale) (11).

\section{SCOPUL ŞI OBIECTIVELE LUCRĂRII}

Studiul efectuat a avut drept obiectiv: identificarea agenţilor etiologici principali ai PAS, observarea limitelor drenajului laparoscopic al PAS şi urmărirea evoluţiei cazurilor în funcţie de tratamentul aplicat, fie el conservator sau chirurgical (minimum invaziv sau deschis). Scopul lucrării a fost acela de a cerceta variabilele în funcţie de care s-a stabilit tipul de management terapeutic, dar mai ales observarea limitelor ce au impus conversia drenajului laparoscopic al PAS (10).

\section{MATERIAL ŞI METODĂ}

Lucrarea a avut la baza un studiu de tip retrospectiv, longitudinal, descriptiv, realizat pe o perioadă de 3 ani (ianuarie 2016-decembrie 2018), fiind analizat un lot total de 132 pacienţi cu pancreatită acută severă internaţi în Clinica de Chirurgie Generală a Spitalului Clinic de Urgenţă Bucureşti. În ceea ce priveşte instrumentele utilizate pentru realizarea bazei de date, s-au utilizat foile de observaţie ale pacienţilor, de mare interes fiind rezultatul examenului CT abdomino-pelvin pentru evidenţierea şi clasificarea PA, protocolul operator ce a descris în detaliu particularitatea fiecărui caz la care s-a intervenit chirurgical, precum şi motivele conversiei tehnicii laparoscopice în 
abord clasic, iar prelucrarea statistică a datelor s-a realizat cu programul Microsoft Excel şi Past 3.

\section{REZULTATE}

Din analiza criteriilor demografice ale lotului studiat, în ceea ce priveşte sexul pacienţilor diagnosticaţi cu PAS, s-a evidenţiat o preponderenţă a genului masculin (83 cazuri), majoritatea provenind din mediul urban şi având o vârstă cuprinsă între minimum 25 ani şi maximum 89 ani, cu o medie a vârstei de 54 ani (Fig. 1).

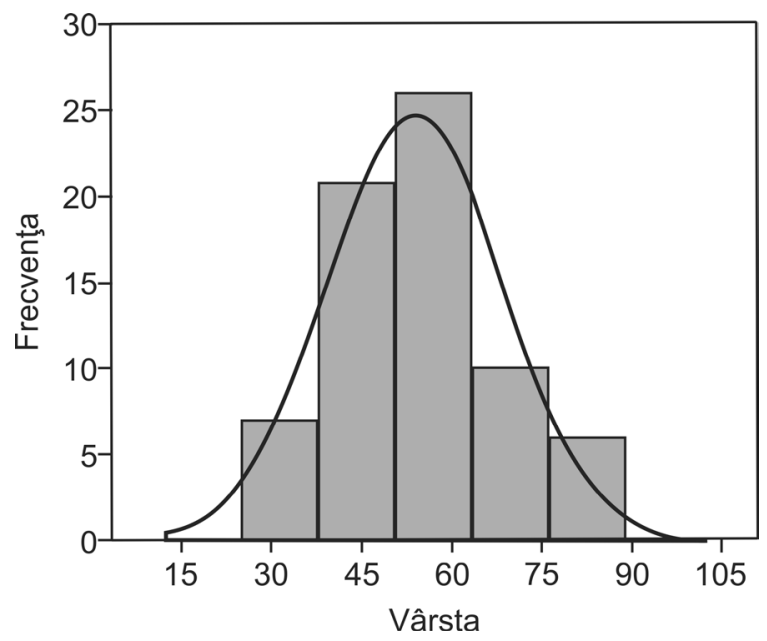

FIGURA 1. Distribuția pacienților în funcție de vârstă

Din punctul de vedere al aspectului morfopatologic, cel mai des s-a evidenţiat PA necrotico-hemoragică infectată (34 cazuri), urmată de PA necrotico-hemoragică neinfectată (26 cazuri), PA necrotică (25 cazuri), PAS cu pseudochist pancreatic (13 cazuri), PA cu aspect edematos (11 cazuri) şi 3 cazuri de PA cronică acutizată cu pseudochist corporeal abce dat.

Suprainfectarea chistului sau a zonelor de necroză pancreatică s-a realizat cel mai frecvent cu $E$. coli (44\%), urmată de Enterococcus (24\%), Proteus spp. (10\%) şi Acinetobacter spp. (10\%) (Fig. 2).

Etiologia pancreatitei acute severe este adesea multiplă, cel mai frecvent fiind provocată de un exces caloric asociat cu abuzul de alcool, evidenţiinduse astfel 95 cazuri de PAS toxic-nutriţională. Litiaza colecisto-coledociană a reprezentat de asemenea un factor etiologic des întâlnit la pacienţii din lotul studiat (34 cazuri), iar pentru 3 pacienţi, o formaţiune tumorală cefalică pancreatică a reprezentat factorul declanşator.

Cei mai mulţi dintre pacienţi au descris la prezentarea în camera de gardă dureri abdominale caracteristice pancreatitei acute (durere în etajul abdominal superior, cu intensitate maximă în epigastru și iradiere „în bară“, cu intensificare rapidă

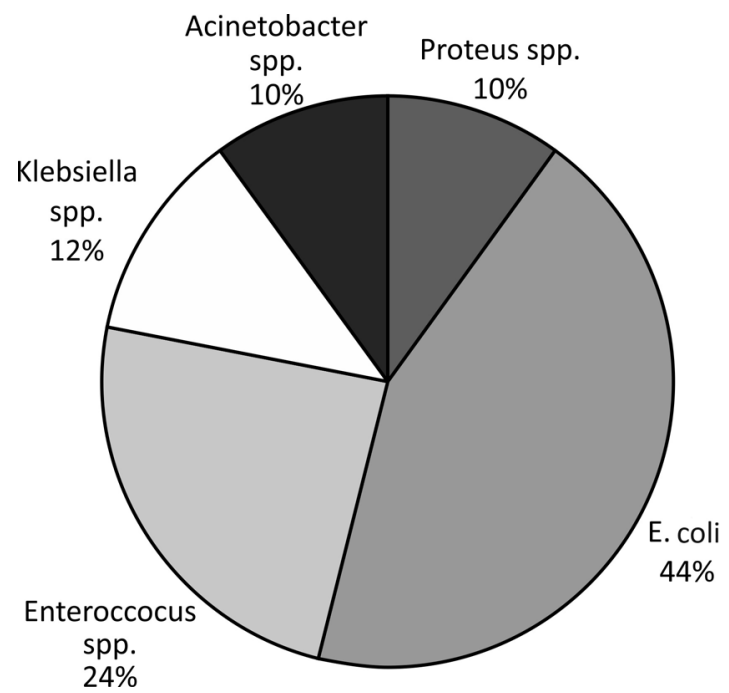

FIGURA 2. Distribuția pacienților în funcție de agentul etiologic al suprainfecției chistului pancreatic

și progresivă +/- vărsături și greață), iar de cele mai multe ori debutul bolii a fost la $>24$ ore de la internare (79 cazuri). În ceea ce priveşte antecedentele personale patologice ale pacienţilor, doar 24\% dintre aceştia au prezentat un alt episod de PA în trecut. Din lotul analizat, 36\% dintre cazuri au avut un IMC modificat, cu obezitate; $33 \%$ au asociat diabet zaharat tip 2 cu control slab, iar $40 \%$ dintre pacienţi erau cunoscuţi cu dislipidemie, având valori modificate ale lipidogramei, cu hipertrigliceridemie, hipercolesterolemie, circumferinţa abdominală crescută şi diabet zaharat tip 2 .

Analizele serologice la debut au prezentat modificări semnificative, $78 \%$ dintre pacienţi prezentând valori crescute ale lipazei (de 3 ori faţă de valoarea normală) şi persistenţa lor mai multe zile, hiperamilazemie (58\%), leucocitoză moderată sau severă (72\%) şi valori crescute ale GGT (61\%) (Fig. 3).

În urma evaluărilor clinice şi paraclinice, cu ajutorul examenului CT abdomino-pelvin, s-au putut evidenţia colecţii peripancreatice fluide, localizarea cea mai frecventă fiind la nivelul rădăcinii mezenterului (24 cazuri), bursa omentală (20 cazuri), perihepatic (14), perisplenic (13), parieto-colic stâng (11), parieto-colic drept (8), retroperitoneal (8), fascie perirenală stângă (13), fascie perirenală dreaptă (7) sau la nivelul marii curburi gastrice (6 cazuri).

Localizarea chistului pancreatic a fost cel mai des cefalică (43\%), corporeo-caudal (19\%), caudal (17 \%), corporeal (12\%) şi corporeo-cefalic (9\%) (Fig. 4).

După efectuarea bilanţului clinic şi paraclinic şi stabilirea unui diagnostic de certitudine, se stabileşte conduita terapeutică; astfel, dintre cele 132 cazuri analizate, 107 cazuri (81\%) au beneficiat de tratament conservator (regim alimentar hidric, monitorizarea funcţiilor vitale şi a constante- 

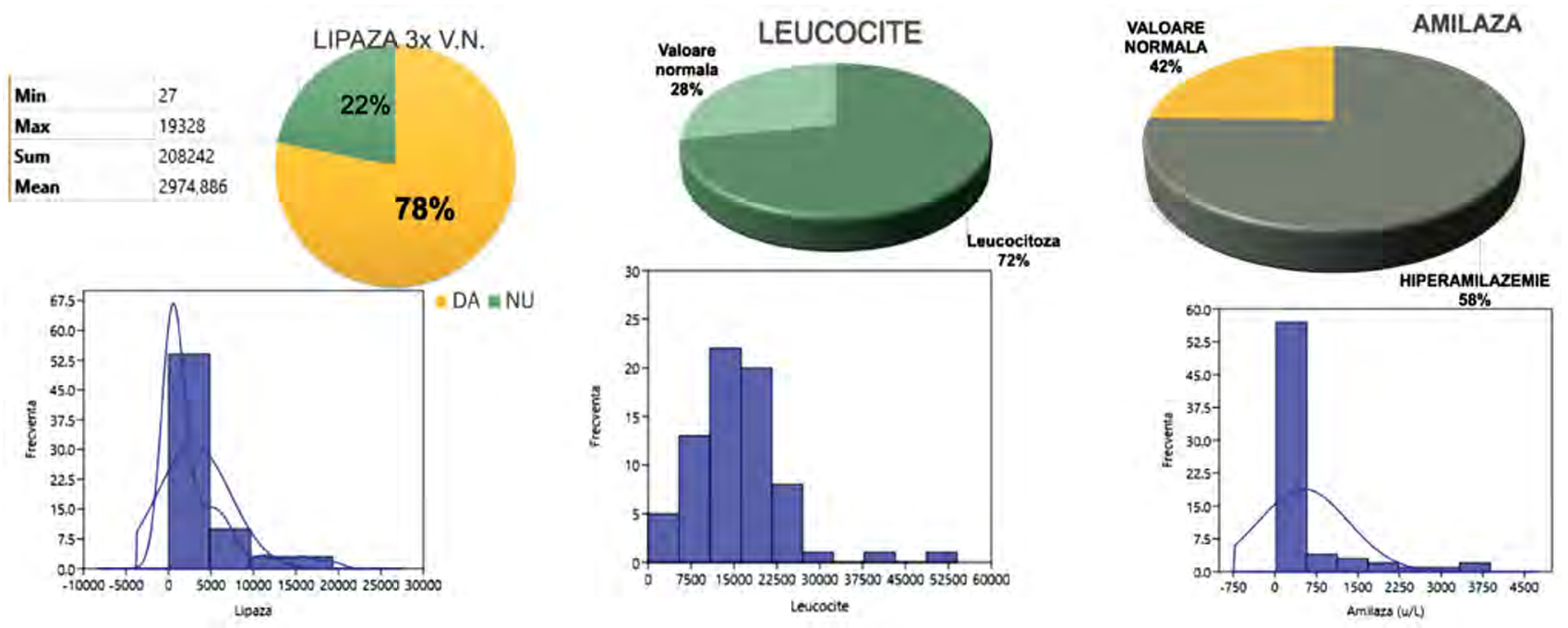

FIGURA 3. Distribuția pacienților în funcție de valorile lipazei, amilazei și leucocitelor

lor serologice) şi 25 cazuri (19\%) au fost supuse intervenţiei chirurgicale.

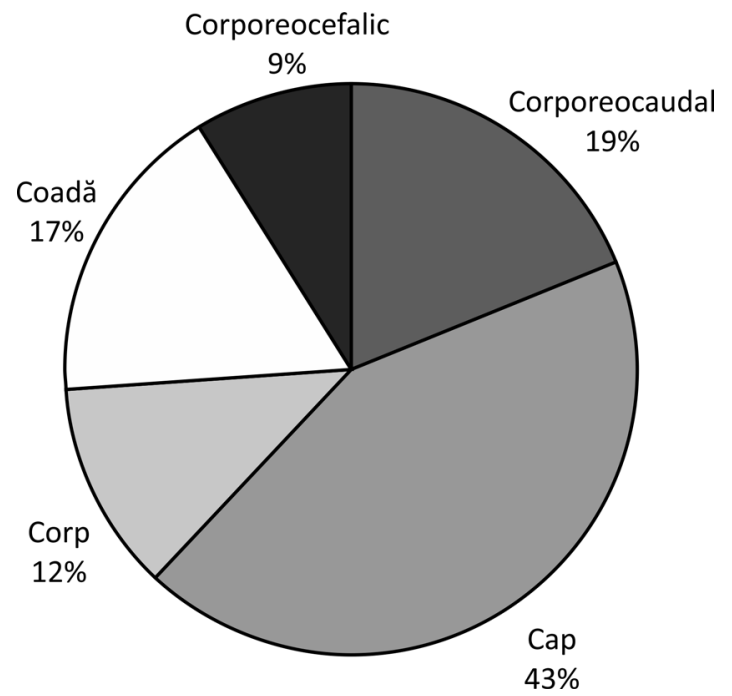

FIGURA 4. Distribuția cazurilor în funcție de localizarea chistului la nivelul pancreasului
Dintre cei la care s-a intervenit chirurgical, în 14 cazuri s-a efectuat necrectomie clasică prin laparotomie exploratorie, excizia zonelor de necroză de la nivel pancreatic şi drenajul cavităţii abdominale, iar 11 cazuri (8\%) s-au pretat pentru abordul laparoscopic al afecţiunii (Fig. 5).

În ceea ce priveşte tratamentul chirurgical clasic al PAS, 5 pacienti au beneficiat de laparotomie exploratorie, necrectomie, lavaj, drenaj peritoneal multiplu; pentru 3 cazuri s-a realizat şi colecistectomie retrogradă, iar drenaj biliar extern transcistic s-a efectuat în 2 cazuri. După laparotomie urmată de necrectomie clasică, la doi pacienţi s-a realizat laparostomă tip Bogota bag. Un pacient a beneficiat de pancreatico-jejunostomie tip Puestow-Gillesby, iar într-un caz s-a realizat anastomoză jejuno-pancreatică cu ansă exclusă în $Y$ à la Roux (operaţia Frey).

Dintre cei 25 pacienţi pentru care s-a aplicat un management chirurgical, 11 cazuri au beneficiat

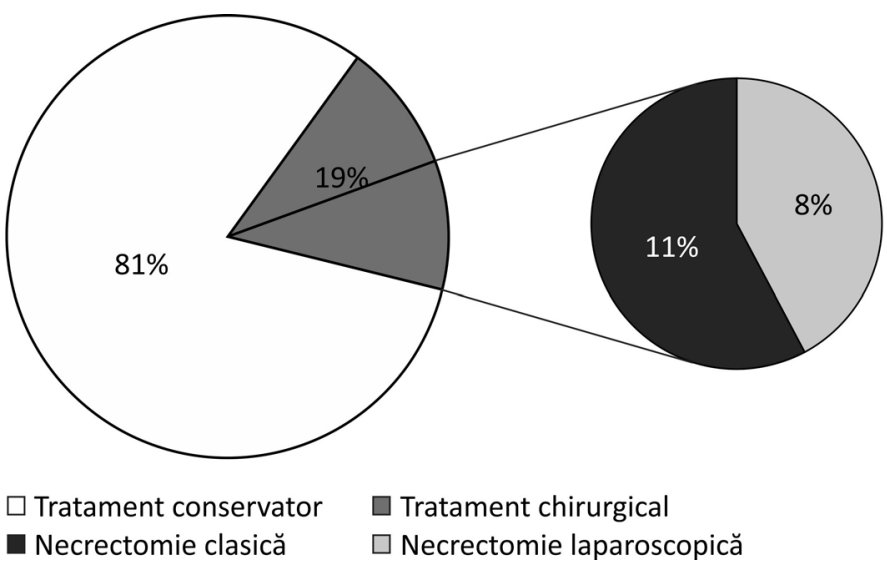

- Tratament conservator = 107 cazuri

- Tratament chirurgical

$=25$ cazuri

a. Necrectomie clasică (14 cazuri)

b. Necrectomie laparoscopică (11 cazuri)

FIGURA 5. Distribuția pacienților în funcție de managementul terapeutic aplicat 
de necrectomie laparoscopică, însă doar pentru 7 pacienţi abordul minimum invaziv s-a menţinut până la finalul intervenţiei, fiind urmat de drenajul extern al colecţiilor lichidiene şi/sau al necrozei pancreatice infectate. Patru dintre aceştia au necesitat conversie.

Printre cauzele de conversie descrise în detaliu în protocoalele operatorii, se numără: prezenţa unei cantităţi mari de lichid liber intraperitoneal difuz distribuit, în toate recesurile (> $1.500 \mathrm{ml}$ ), anatomia dificilă şi prezenţa de abcese retroperitoneale descrise la examenul computer tomograf, însă nevizualizabile laparoscopic, intens proces de periviscerită entero-enterală şi entero-parietală, cu evidenţierea la nivelul abdomenului superior a unui bloc inflamator ce ocupă epigastrul şi hipocondrul drept şi stâng şi prezenţa aderenţelor între pancreas şi faţa posterioară a stomacului, făcând imposibilă evidenţierea laparoscopică a pseudochistului pancreatic.

Postoperator, evoluţia cazurilor a fost favorabilă, existând şi excepţii, cazuri a căror evoluţie a fost lent favorabilă prin apariţia de complicaţii, precum: anemia moderată, pleurezia bazală stângă cu atelectazie în bandă postero-bazală, colita cu Clostridium difficile, persistenţa drenajelor peritoneale cu debit crescut, disfuncţia multiplă de organ sau fistula duodenală cu debit mediu, însă fără expresie clinică, evidenţiată doar prin exteriorizarea de albastru de metilen la nivelul tubului de dren.

Intervalul de timp de spitalizare a atins un maximum de 98 zile, un minimum de 11 zile şi o medie de 20,4 zile. La externare, din lotul studiat, cei mai mulţi dintre ei au prezentat un status ameliorat (55\%), 23\% s-au vindecat şi decesul s-a inregistrat pentru $20 \%$ dintre aceştia. Evaluarea mortalităţii la 30 zile a pacienţilor cu PAS a evidenţiat o evoluţie favorabilă pentru 122 cazuri, doar 14 pacienţi prezentând evoluţie nefavorabilă, cu exitus la o lună.

\section{DISCUȚII}

PAS este 0 patologie ce necesită tratament susţinut, rapid şi eficient, consumul de etanol fiind cel mai des incriminat, iar tipul morfopatologic cel mai frecvent întâlnit fiind PAS necrotico-hemoragică infectată, cu implicaţii atât locale, cât şi sistemice, evoluţie rapid nefavorabilă şi prognostic rezervat, fiind însoţit de o rată ridicată a mortalităţii.
Studiul lui Buchler, efectuat în anul 2000 în Elveţia, a identificat drept cauză principală a episoadelor de PAS prezenţa litiazei biliare (5).

E. coli este cel mai des agentul etiologic de suprainfecţie a pseudochistului pancreatic. Rezultatele obţinute în studiul realizat de către Buchler sunt diferite, suprainfecţia chistului pancreatic sau a colectriilor peripancreatice s-au realizat cel mai frecvent cu Staphylococcus spp. (36\%), urmată de Candida (17\%) (5).

În ceea ce priveşte tabloul clinic, simptomatologia dureroasă nu este întotdeauna caracteristică, iar diabetul zaharat tip 2, obezitatea sau dislipidemia sunt factori ce favorizează şi pregătesc terenul dezvoltării unei astfel de patologii.

Colecţiile fluide peripancreatice se localizează frecvent în bursa omentală şi la nivelul rădăcinii mezenterului, iar chistul pancreatic prezintă frecvent localizare cefalică. Alte complicaţii observate în studiul din Elveţia care s-au regăsit şi în studiul nostru au fost: pseudochistul pancreatic, sângerarea şi fistula pancreatică.

Tratamentul conservator este o alegere eficientă în managementul pacienţilor cu PAS, iar intervenţia chirurgicală prin abord laparoscopic este o metodă fezabilă în cazurile selecţionate, eficientă şi puţin traumatică, ce favorizează o evoluţie bună a cazurilor, mobilizare rapidă şi scade rata complicaţiilor cauzate de cicatricea mare postoperatorie cum este în cazul operaţiilor clasice (evisceraţii, eventraţii, sângerări, serom, hematoame). Intervenţia chirurgicală este temporizată pentru cazurile de PAS şi în studiile din literatura de specialitate, tratamentul conservator fiind iniţial de primă intenţie, cu monitorizarea atentă a pacientului şi sesizarea factorilor ce anunţă apariţia complicaţiilor ce impun aplicarea unei conduite terapeutice severe, invazive (12).

Conversia către chirurgia clasică se impune în caz de anatomie neclară, lichid liber în cantitate mare intraabdominal, proces intens de periviscerită în etajul abdominal superior, aderenţe între pancreas şi stomac care fac imposibilă evidenţierea pseudochistului pancreatic.

\section{CONCLUZIE}

Abordul laparoscopic poate fi o alternativă terapeutică în tratamentul pancreatitei acute severe în cazuri selecţionate.

Conflict of interest: none declared Financial support: none declared 


\section{BIBLIOGRAFIE}

1. Hartwig W, Werner J, Uhl W, Buchler W. Management of infection in acute pancreatitis. J Hepatobiliary Pancreat SURG. 2002; 9:423-428.

2. Zhou ZG, Zheng YC, Shu $Y$ et al. Laparoscopic management of severe acute pancreatitis. Pancreas. 2003 Oct; 27 (3): e46-50.

3. Beger HG, Rau MB. Severe acute pancreatitis: Clinical course and management. World J. Gastroenterol. 2007 Oct 14; 13(38):5043-5051.

4. Pavars M, Irmejs A, Maurins U, Gardovskis J. Severe acute pancreatitis: Role for laparoscopic surgery. Zentralb/ Chir. 2003 Oct; 128(10):858-861.

5. Buchler MW, Gloor B, Muller AC, Friess $H$, Seller AC, Uhl W. Acute Necrotizing
Pancreatitis: Treatment Strategy According to the status of Infection. Annals of Surgery. 2000; 232 (5):619-626.

6. Zerem E. Treatment of severe acute pancreatitis and its complications. World $\mathrm{J}$ Gastroenterol. 2014 Oct 14; 20(38):1387913892.

7. Wronski M, Cebulski W, Slodkowski M, Krasnodebski W. Minimally invasive treatment of infected pancreatic necrosis. Prz Gastroenterol 2014; 9(6):317-324.

8. Bucher Pascal, Pugin François, Philippe Morel. Minimally Invasive Necrosectomy for Infected Necrotizing Pancreatitis. Pancreas. 2008 March. Vol. 36(2):113-119.

9. Lerch MM, Stier A, Wahnschaffe U, Mayerle J. Pancreatic Pseudocysts. Observation, Endoscopic drainage, or Resection?
Deutsches Arzteblatt International 2009; 106(38):614-620.

10. Worhunsky JD, Qadan M, Dua M, Park GW et al. Laparoscopic Transgastric Necrosectomy for the Management of pancreatic Necrosis. Journal of the American College of Surgeons 2014; 2-20.

11. Bausch D, Wellner U, Kahl S et al. Minimally invasive operations for acute necrotizing pancreatitis. Comparison of minimally invasive retroperitoneal necrosectomy with endoscopic transgastric necrosectomy. J. Surg 2012; Vol. 152 (3S):129-132.

12. 12. Babu RY, Gupta R, Kang M et al. Predictors of surgery in patients with severe acute pancreatitis managed by the step-up approach. Ann Surg. 2013 Apr; 257(4):737-750. 